\title{
Activation of RAW264.7 mouse macrophage cells in vitro through treatment with recombinant ricin toxin-binding subunit B: Involvement of protein tyrosine, NF-кB and JAK-STAT kinase signaling pathways
}

\author{
NA XU ${ }^{1-3^{*}}$, HONGYAN YUAN ${ }^{1 *}$, WENSEN LIU ${ }^{2 *}$, SONGYAN LI ${ }^{2}$, YANG LIU ${ }^{1}$, \\ JIAYU WAN $^{2}$, XIAOYAN $\mathrm{LI}^{2}$, RUI ZHANG ${ }^{2}$ and YAPING CHANG $^{1}$ \\ ${ }^{1}$ Department of Immunology, Norman Bethune College of Medical Science, Jilin University; \\ ${ }^{2}$ Institute of Military Veterinary Sciences, Academy of Military Medical Sciences; \\ ${ }^{3}$ Dean's Office, Jilin Medical College, Jilin, P.R. China
}

Received April 3, 2013; Accepted June 18, 2013

DOI: $10.3892 /$ ijmm.2013.1426

\begin{abstract}
Ricin toxin-binding subunit B (RTB) is a galactosebinding lectin protein. In the present study, we investigated the effects of RTB on inducible nitric oxide (NO) synthase (iNOS), interleukin (IL)-6 and tumor necrosis factor (TNF)- $\alpha$, as well as the signal transduction mechanisms involved in recombinant RTB-induced macrophage activation. RAW264.7 macrophages were treated with RTB. The results revealed that the mRNA and protein expression of iNOS was increased in the recombinant RTB-treated macrophages. TNF- $\alpha$ production was observed to peak at $20 \mathrm{~h}$, whereas the production of IL-6 peaked at $24 \mathrm{~h}$. In another set of cultures, the cells were co-incubated with RTB and the tyrosine kinase inhibitor, genistein, the phosphatidylinositol 3-kinase (PI3K) inhibitor, LY294002, the p42/44 inhibitor, PD98059, the p38 inhibitor, SB203580, the JNK inhibitor, SP600125, the protein kinase C (PKC) inhibitor, staurosporine, the JAK2 inhibitor, tyrphostin (AG490), or the NOS inhibitor, L-NMMA. The recombinant RTB-induced production of NO, TNF- $\alpha$ and IL- 6 was inhibited in the macrophages treated with the pharmacological inhibitors
\end{abstract}

Correspondence to: Professor Wensen Liu, Institute of Military Veterinary Sciences, Academy of Military Medical Sciences, 666 West Liuying Road, Changchun, Jilin 130122, P.R. China

E-mail: liuws85952@163.com

Professor Yaping Chang, Department of Immunology, Norman Bethune College of Medical Science, Jilin University, 126 Xinmin Street, Changchun, Jilin 130122, P.R. China

E-mail: changyp@jlu.edu.cn

*Contributed equally

Key words: ricin toxin-binding subunit B, macrophage activation, nitric oxide genistein, LY294002, staurosporine, AG490, SB203580 and BAY 11-7082, indicating the possible involvement of protein tyrosine kinases, PI3K, PKC, JAK2, p38 mitogen-activated protein kinase (MAPK) and nuclear factor $(\mathrm{NF})-\kappa \mathrm{B}$ in the above processes. A phosphoprotein analysis identified tyrosine phosphorylation targets that were uniquely induced by recombinant RTB and inhibited following treatment with genistein; some of these proteins are associated with the downstream cascades of activated JAK-STAT and NF- $\kappa$ B receptors. Our data may help to identify the most important target molecules for the development of novel drug therapies.

\section{Introduction}

Ricin is a $65-\mathrm{kDa}$ glycoprotein toxin produced by the seeds of Ricinus communis and has been classified as a ribosome-inactivating protein (RIP) (1). Ricin consists of a cytotoxic A chain (RTA) and a galactose-binding B chain (RTB) linked by a disulfide bond (2). The A-chain is $32 \mathrm{kDa}$, targets the ribosome and inhibits protein synthesis in mammalian cells; the B-chain is $34 \mathrm{kDa}$ and is a galactose-binding lectin protein that binds to the eukaryotic cell membrane by interacting with cell-surface molecules, such as galactose and glycolipids $(3,4)$. RTB mediates ricin endocytosis and the delivery of RTA to the cytosol of target cells, and RTB has attracted attention due to its wellcharacterized endocytotic trafficking and efficacy over a wide range of cell types $(5,6)$. Studies have shown that RTB can be successfully used as a carrier fused to other molecules. When RTB was fused to rotavirus nonstructural protein 4 (NSP4), the molecule stimulated a Th1 lymphocyte response (7). In addition, an RTB-GFP fusion protein expressed in tobacco has been shown to generate humoral immune responses in immunized mice, indicating a Th2 response (8). However, an understanding of the immune response induced by RTB is necessary to determine the mechanisms by which RTB acts as an immunostimulant.

Macrophages play an important role in the activation of the adaptive immune system by responding to pathogens, 
tumor cells and toxicants by changing from a resting to an activated state (9-11). Upon activation, macrophages produce many types of inflammatory mediators, such as interleukin (IL)-6, tumor necrosis factor (TNF)- $\alpha$, and nitric oxide (NO) molecules that are central to the immunoregulatory function of macrophages (12-14).

The NO produced by inducible NOS (iNOS) is a major acute and chronic inflammatory mediator $(15,16)$. Indeed, the NO released by activated macrophages mediates a number of host-defense functions and contributes to immune-mediated tissue destruction disorders $(17,18)$.

In the present study, we investigated the effects of RTB on iNOS, IL- 6 and TNF- $\alpha$, as well as the signal transduction mechanisms involved in recombinant RTB-induced macrophage activation. This may help to identify the most important target molecules for the development of novel drug therapies.

\section{Materials and methods}

Materials. RTB was cloned and express in Escherichia coli. The protein was purified using nickel-NTA column chromatography. Lipopolysaccharide (LPS) contamination was $<0.03 \mathrm{pg} / \mu \mathrm{g}$ protein for recombinant RTB as determined by the Limulus amebocyte lysate assay (BioWhittaker, Inc., Walkersville, MD, USA). L-N monomethyl arginine (L-NMMA), genistein, SB203580, LY294002 and BAY 11-7082 were obtained from Sigma (St. Louis, MO, USA). Antibodies against iNOS were purchased from Cell Signaling Technology, Inc. (Danvers, MA, USA) and the one-step RT-PCR kit was purchased from Takara Bio, Inc. (Shiga, Japan).

Cell culture. RAW264.7 cells were cultured in RPMI-1640 medium supplemented with $10 \%$ fetal calf serum (FCS) (HyClone, Logan, UT, USA), $100 \mathrm{U} / \mathrm{ml}$ penicillin and $100 \mathrm{U} / \mathrm{ml}$ streptomycin at $37^{\circ} \mathrm{C}$ in a humidified atmosphere of $5 \% \mathrm{CO}_{2}$. Cells were seeded in 24-well plates and allowed to grow overnight, then treated with fresh medium or different concentrations of RTB. In another set of cultures, the cells were co-incubated with RTB $(10 \mu \mathrm{g} / \mathrm{ml})$ and the tyrosine kinase inhibitor, genistein $(10 \mu \mathrm{M})$, the phosphatidylinositol 3-kinase (PI3K) inhibitorm LY294002 $(10 \mu \mathrm{M})$, the p42/44 inhibitor, PD98059 $(50 \mu \mathrm{M})$, the p38 inhibitor, SB203580 (4 $\mu \mathrm{M})$, the JNK inhibitor, SP600125 $(10 \mu \mathrm{M})$, the protein kinase C (PKC) inhibitor, staurosporine (50 nM), the JAK2 inhibitor, tyrphostin (AG490) $(25 \mu \mathrm{M})$, or the NOS inhibitor, L-NMMA $(500 \mu \mathrm{M})$.

Western blot analysis. The RAW264.7 cells were treated with RTB for the indicated periods of time, collected and lysed in $100 \mu 1$ RIPA lysis buffer (Beyotime Biotechnology, Shanghai, China) for $30 \mathrm{~min}$ at $4^{\circ} \mathrm{C}$. The lysates were centrifuged at $15,000 \mathrm{x} \mathrm{g}$ for $20 \mathrm{~min}$ at $4^{\circ} \mathrm{C}$, and the protein content of the lysates was determined using a BCA assay kit (Beyotime Biotechnology). The protein supernatants were separated by 10\% SDS-PAGE and transferred onto polyvinylidene fluoride (PVDF) membranes (Millipore, Billerica, MA, USA). The membranes were blocked with $5 \%$ non-fat milk (Becton, Dickinson and Co., Oxford, UK) in PBS for $1 \mathrm{~h}$ at room temperature and incubated with anti-iNOS and then secondary antibodies. Immunodetection was performed using Amersham ECL $^{\mathrm{TM}}$ Western Blotting Detection Reagents (GE Healthcare,
Chalfont St. Giles, UK) according to the manufacturer's instructions.

RT-PCR analysis. Total RNA was isolated from $1 \times 10^{6} \mathrm{RAW} 264.7$ cells using TRIzol reagent. RT-PCR analysis of the mRNA expression of iNOS, IL-6 and TNF- $\alpha$ was performed using one-step RT-PCR kits. GADPH was used as the housekeeping gene. The primer sequences used were as follows: iNOS forward, 5'-CTGCAGCACTTGGATCAGGAAGCTG-3' and reverse, 5'-GGGAGTAGCCTGTGTGCACCTCGAA-3'; IL-6 forward, 5'-TTCCCTACTTCACAAGTC-3' and reverse, 5'-ACTAGGTTTGCCGAGTAG-3'; and TNF- $\alpha$ forward, 5'-TTCTGTCTACTGAACTTCGGGGTGATCGGTCC-3' and reverse, 5'-GTATGAGATAGCAAATCGGCTGACGGTGT GGG-3'. The conditions for PCR were 30 cycles of $94^{\circ} \mathrm{C}$ denaturation for $30 \mathrm{sec}, 60^{\circ} \mathrm{C}$ annealing for $30 \mathrm{sec}$ and $72^{\circ} \mathrm{C}$ extension for $60 \mathrm{sec}$. The PCR products were analyzed by electrophoresis on $1.5 \%$ agarose gels stained with ethidium bromide. The relative quantification of mRNA expression was performed using $\beta$-actin as an internal control to normalize the gene expression for the PCR templates.

Cytokine ELISA. The RAW264.7 cells were treated with RTB in the presence or absence of different inhibitors, and the expression of IL- 6 and TNF- $\alpha$ in the culture supernatant was measured using ELISA kits (BioLegend, San Diego, CA, USA).

NO production assay. The RAW264.7 cells were treated with RTB in the presence of different inhibitors. NO generation was determined using Griess reagent (Beyotime Biotechnology), with nitrite production measured as the absorbance at $540 \mathrm{~nm}$.

Phospho-specific protein microarray analysis. Phosphoprotein arrays were obtained from Full Moon Biosystems (Sunnyvale, CA, USA) and 228 site-specific tyrosine phosphorylation profiles were detected with 6 replicates each. The protein samples were biotinylated using Tyrosine Phosphorylation ProArray (Full Moon BioSystems), and the biotin-labeled protein samples were conjugated to antibodies using the Array Assay Kit (Full Moon BioSystems). The conjugated, labeled protein was detected using Cy3-streptavidin. Antibody array slides were scanned using the GenePix 4000 B microarray scanner (Axon Instruments, Union City, CA, USA). For data analysis, the fold change in intensity of the 6 replicates was measured using GenePix Pro 6.0 software (Axon Instruments). After being divided by the averaged actin value in each experiment, the changes in the phosphorylation rate following treatment with RTB and tyrosine kinase inhibitor (genistein) was computed as follows: increasing phosphorylation ratio $=($ average value with $\mathrm{RTB}$ treatment $) /$ average value without RTB treatment; decreasing phosphorylation ratio $=$ (average value with inhibitor treatment - average value without inhibitor treatment)/average value without inhibitor treatment.

Statistical analysis. The data are presented as the means \pm SD. The differences between the groups were analyzed using a paired Student's t-test. A p-value $<0.05$ was considered to indicate a statistically significant difference; and $\mathrm{p}<0.01$ a highly statistically significant difference. 
A
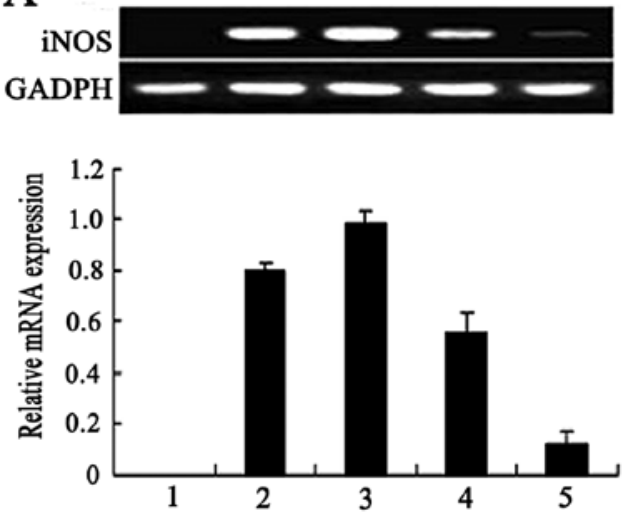

B
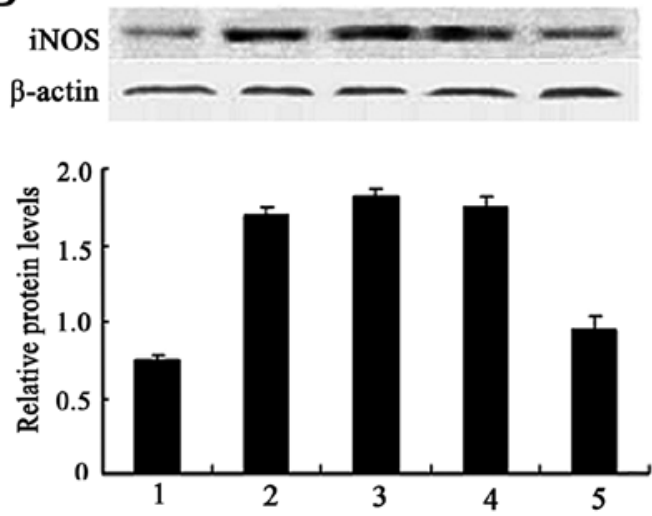

Figure 1. Effect of ricin toxin-binding subunit B (RTB) on the mRNA and protein expression of increased inducible nitric oxide (NO) synthase (iNOS) in RAW264.7 cells. Cells were incubated with RTB $(1,10,100 \mu \mathrm{g} / \mathrm{ml})$ or lipopolysaccharide (LPS) (50 ng/ml) for $24 \mathrm{~h}$. (A) Total RNA was isolated and the mRNA expression was examined by RT-PCR. Lane 1, untreated macrophages; lane 2, LPS (50 ng/ml); lane 3, RTB (100 g/ml); lane 4, RTB (10 $\mu \mathrm{g} / \mathrm{ml})$; lane 5, RTB (1 $\mu \mathrm{g} / \mathrm{ml})$. (B) Cell lysates were prepared and iNOS protein expression was examined by western blot analysis. The lower panel represents the expression of GADPH and actin. Lane 1 , untreated macrophages; lane 2, LPS (50 ng/ml); lane 3, RTB (100 $\mu \mathrm{g} / \mathrm{ml})$; lane 4, RTB $(10 \mu \mathrm{g} / \mathrm{ml})$; lane 5, RTB $(1 \mu \mathrm{g} / \mathrm{ml})$. Shown are representative results from $1 \mathrm{of}$ 3 experiments with similar results. Densitometric analysis showing the relative intensity of the bands; relative ratios vs. GADPH or actin.

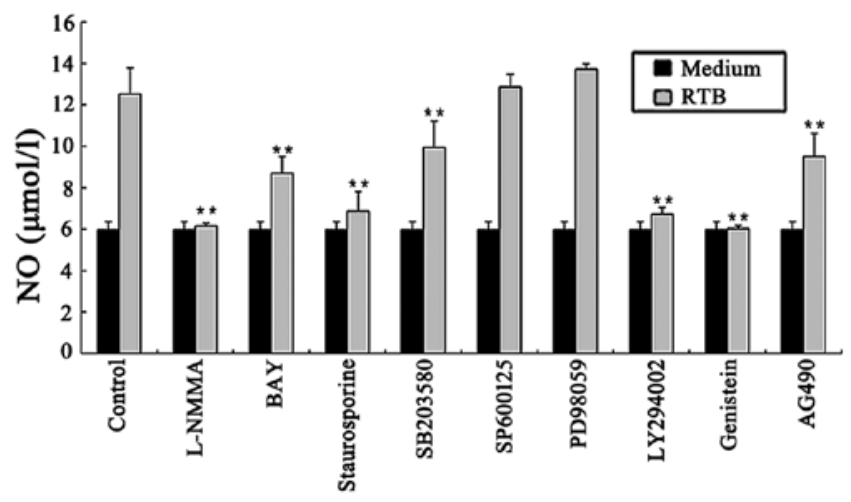

Figure 2. Effect of different inhibitors on ricin toxin-binding subunit B (RTB)-induced nitric oxide (NO) production in RAW264.7 cells. Following pre-treatment with various inhibitors for $1 \mathrm{~h}$, the RAW264.7 cells were treated with RTB $(10 \mu \mathrm{g} / \mathrm{ml})$ for $24 \mathrm{~h}$. The culture supernatants were collected and analyzed for nitrite production. The results are presented as the means \pm SD of 3 independent experiments. ${ }^{*} \mathrm{p}<0.01$ compared with the control group.

\section{Results}

Effects of RTB on iNOS expression in RAW264.7 cells. In the RAW264.7 cells treated with RTB, the mRNA and protein expression levels of iNOS increased in a dose-dependent manner, as observed by RT-PCR (Fig. 1A) and western blot analysis (Fig. 1B). The mRNA and protein expression of iNOS in the cells treated with LPS $(50 \mathrm{ng} / \mathrm{ml})$ was used as the positive control. The addition of the iNOS inhibitor, L-NMMA $(500 \mu \mathrm{M})$, decreased the NO production and iNOS mRNA synthesis induced by RTB (Fig. 2 and 3A).

Role of protein kinases in NO production in RTB-treated RAW264.7 cells. The RAW264.7 cells treated with RTB $(10 \mu \mathrm{g} / \mathrm{ml})$ in the presence of genistein, SB203580, LY294002, or staurosporine for $24 \mathrm{~h}$ exhibited reduced NO production (Fig. 2). Similar results were obtained for the mRNA expression of iNOS by RT-PCR (Fig. 3A and B). Of note, the mitogen- activated protein kinase (MAPK) inhibitors, PD98059 and SP600125, did not affect the observed RTB-induced NO production (Fig. 2).

Role of the JAK-STAT pathway in NO production in RTB-treated RAW264.7 cells. The RAW264.7 cells treated with RTB $(10 \mu \mathrm{g} / \mathrm{ml})$ in the presence of the JAK2 inhibitor, tyrphostin (AG490), for 24 h showed a decreased NO production (Fig. 2). Similar results were obtained for the mRNA expression of iNOS (Fig. 3C).

Role of the nuclear factor $(N F)-\kappa B$ pathway in NO production in RTB-treated RAW264.7 cells. The treatment of RAW264.7 cells with RTB $(10 \mu \mathrm{g} / \mathrm{ml})$ in the presence of the NF- $\kappa \mathrm{B}$ inhibitor, BAY 11-7082, for $24 \mathrm{~h}$ resulted in the inhibition of NO production (Fig. 2). Similar results were obtained for the mRNA expression of iNOS (Fig. 3A).

Time kinetics of TNF- $\alpha$ and IL-6 expression induced by RTB. The concentrations of TNF- $\alpha$ and IL- 6 stimulated by RTB $(10 \mu \mathrm{g} / \mathrm{ml})$ were increased at different time intervals, with TNF- $\alpha$ maximum production at $20 \mathrm{~h}$ and IL- 6 maximum production at $24 \mathrm{~h}$ (Fig. 4).

Role of protein tyrosine kinases, JAK-STAT and NF- $\kappa B$ signaling in the production of TNF- $\alpha$ and IL- 6 in RTB-treated RAW264.7 cells. The production of TNF- $\alpha$ and IL-6 induced by RTB was inhibited by the co-treatment with genistein, SB203580, LY294002, BAY 11-7082, staurosporine and AG490 (Fig. 5). Similar effects were observed as regards TNF- $\alpha$ and IL-6 gene transcription (Fig. 6).

Role of NO in the modulation of TNF- $\alpha$ and IL- 6 production in RTB-treated RAW264.7 cells. The treatment of RAW264.7 cells with RTB $(10 \mu \mathrm{g} / \mathrm{ml})$ in the presence of the NOS inhibitor, L-NMMA, had no affect on the mRNA and protein expression of TNF- $\alpha$ and IL-6 (Fig. 5 and 6A). 
A
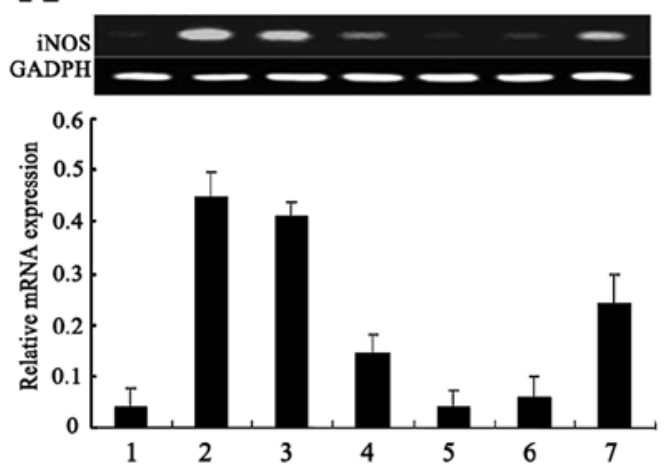

B
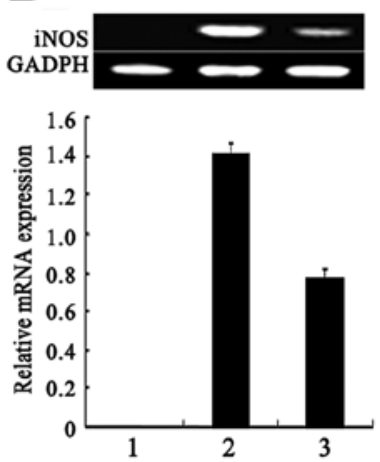

C
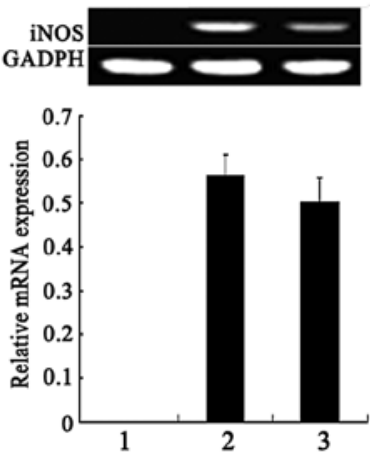

Figure 3. Effect of different inhibitors on the mRNA expression of increased inducible nitric oxide (NO) synthase NOS (iNOS) in ricin toxin-binding subunit B (RTB)-treated RAW264.7 cells. Following pre-treatment with various inhibitors for $1 \mathrm{~h}$, the RAW264.7 cells were treated with RTB (10 $\mu \mathrm{g} / \mathrm{ml})$ for $24 \mathrm{~h}$. iNOS mRNA expression were examined by RT-PCR. (A) Effect of SB203580, genistein, LY294002, L-N monomethyl arginine (L-NMMA) and BAY on the mRNA expression of iNOS in the RTB-treated RAW264.7 cells. Lane 1, untreated macrophages; lane 2, RTB (10 $\mu \mathrm{g} / \mathrm{ml}) ;$ lane 3, RTB + SB203580 (500 $\mu \mathrm{M})$; lane 4 , RTB + genistein $(10 \mu \mathrm{M})$; lane 5, RTB + LY294002 $(10 \mu \mathrm{M})$; lane 6, RTB + L-NMMA $(500 \mu \mathrm{M})$; lane 7, RTB + BAY (100 $\mu \mathrm{M})$. (B) Effect of staurosporine on the mRNA expression of iNOS in RTB-treated RAW264.7 cells. Lane 1, untreated macrophages; lane 2, RTB (10 $\mu \mathrm{g} / \mathrm{ml}) ;$ lane 3, RTB + staurosporine $(50 \mathrm{nM})$. (C) Effect of AG490 on the mRNA expression of iNOS in RTB-treated RAW264.7 cells. Lane 1, untreated macrophages; lane 2, RTB (10 $\mu \mathrm{g} / \mathrm{ml})$; lane 3, RTB + AG490 $(25 \mu \mathrm{M})$. The lower panel represents the expression of GADPH and actin. The results are representative of 1 of 3 experiments with similar results. Densitometric analysis showing the relative intensity of the bands; relative ratios vs. GADPH.

A

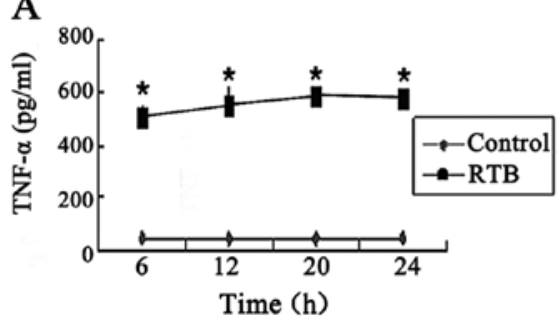

B

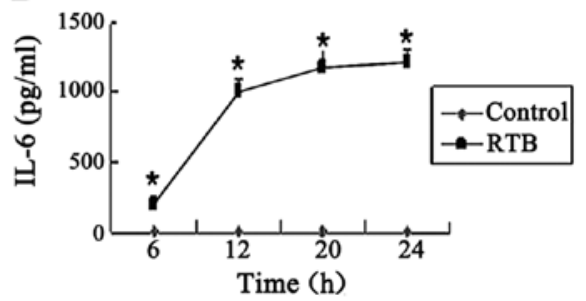

Figure 4. Time kinetics of ricin toxin-binding subunit B (RTB) induced production of tumor necrosis factor (TNF)- $\alpha$ and interleukin-6 (IL-6) in RAW264.7 cells. RAW264.7 cells were treated with or without RTB $(10 \mu \mathrm{g} / \mathrm{ml})$ for different periods of time. TNF- $\alpha$ and IL-6 production was measured by ELISA. Data are presented as the means $\pm \mathrm{SD}$ of 3 replicates. " $\mathrm{p}<0.01$ compared with the control group.

A

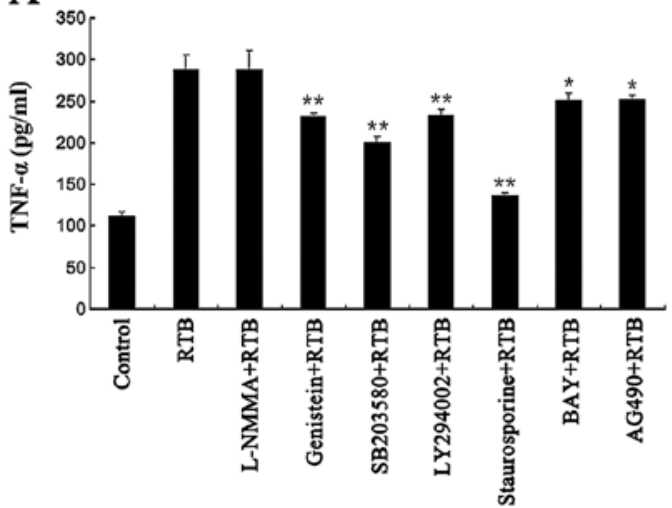

B

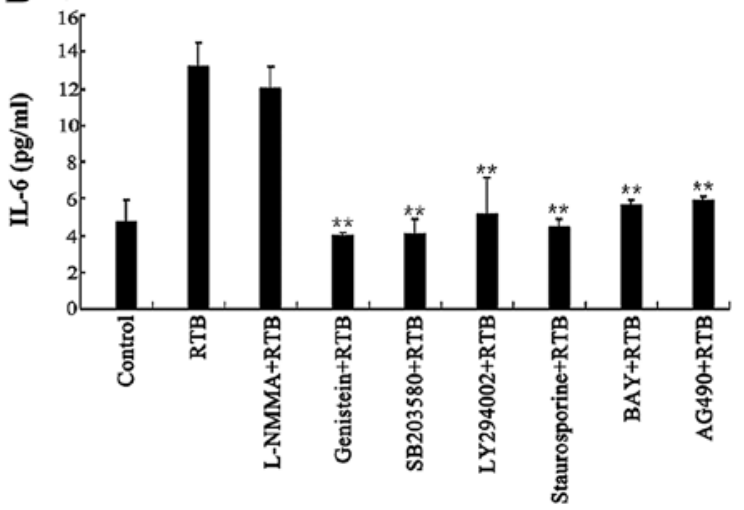

Figure 5. Effect of L-N monomethyl arginine (L-NMMA), genistein, SB203580, LY294002, BAY 11-7082, staurosporine and AG490 on the production of tumor necrosis factor (TNF)- $\alpha$ and interleukin-6 (IL-6) in RTB treated RAW264.7 cells. Following pre-treatment with various inhibitors for $1 \mathrm{~h}$, the RAW264.7 cells were treated with ricin toxin-binding subunit B (RTB) $(10 \mu \mathrm{g} / \mathrm{ml})$ for $24 \mathrm{~h}$. TNF- $\alpha$ and IL- 6 expression were examined by ELISA. Data are presented as the means \pm SD of 3 replicates. ${ }^{*} \mathrm{p}<0.05$ compared with the RTB group, ${ }^{* *} \mathrm{p}<0.01$ compared with the RTB group.

The viability of the RAW264.7 cells was not affected by the dose of the inhibitor used in any of these experiments (data not shown).
Tyrosine phosphorylation levels in RTB-treated RAW264.7 cells. Using a phosphoarray, we analyzed the tyrosine phosphorylation profiles of RTB-treated RAW264.7 cells with or without 
A
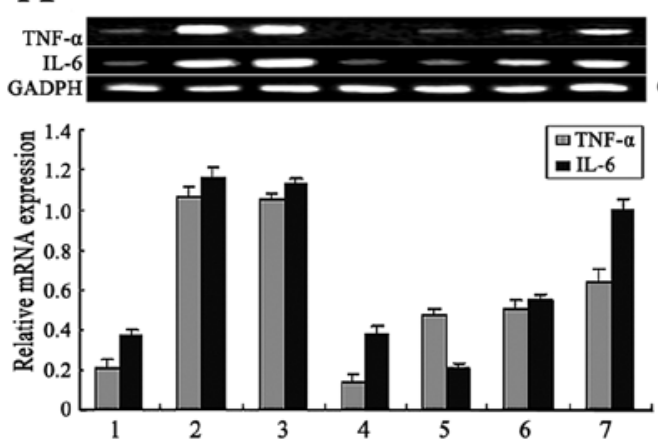

B
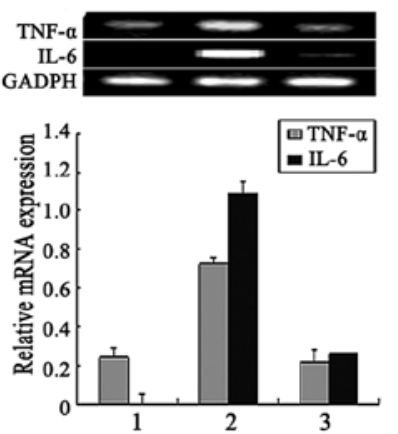

$\mathrm{C}$
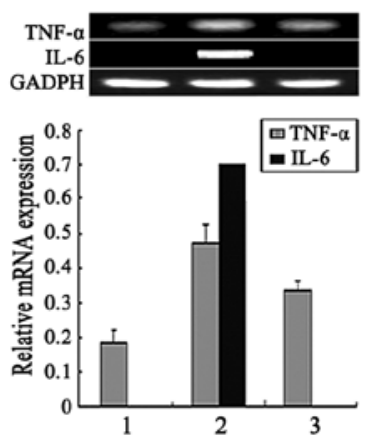

Figure 6. Effect of different inhibitors on the mRNA expression of tumor necrosis factor (TNF)- $\alpha$ and interleukin-6 (IL-6) in ricin toxin-binding subunit B (RTB)-treated RAW264.7 cells. Following pre-treatment with various inhibitors for $1 \mathrm{~h}$, the RAW264.7 cells were treated with RTB (10 $\mu$ g/ml) for 24 h. TNF- $\alpha$ and IL-6 mRNA expression were examined by RT-PCR. (A) Effect of L-N monomethyl arginine (L-NMMA), genistein, SB203580, LY294002 and BAY 11-7082 on the mRNA expression of TNF- $\alpha$ and IL-6 in the RTB-treated RAW264.7 cells. Lane 1, untreated macrophages; lane 2, RTB (10 $\mu \mathrm{g} / \mathrm{ml})$; lane 3, RTB + L-NMMA $(500 \mu \mathrm{M})$; lane 4, RTB + genistein $(10 \mu \mathrm{M})$; lane 5, RTB + SB203580 $(500 \mu \mathrm{M})$; lane 6, RTB + LY294002 $(10 \mu \mathrm{M})$; lane 7 , $\mathrm{RTB}+\mathrm{BAY}(100 \mu \mathrm{M})$. The lower panel represents the expression of GADPH. The results are representative of 3 experiments with similar results. (B) Effect of staurosporine on the mRNA expression of TNF- $\alpha$ and IL-6 in the RTB-treated RAW264.7 cells. Lane 1, untreated macrophages; lane 2 , RTB (10 $\mu \mathrm{g} / \mathrm{ml}$ ); lane 3, RTB + staurosporine (50 nM). (C) Effect of AG490 on the mRNA expression of TNF- $\alpha$ and IL-6 in the RTB-treated RAW264.7 cells. Lane 1, untreated macrophages; lane 2, RTB $(10 \mu \mathrm{g} / \mathrm{ml})$; lane 3, RTB + AG490 $(25 \mu \mathrm{M})$. The lower panel represents the expression of GADPH and actin. The results are representative of 1 of 3 experiments with similar results. Densitometric analysis showing the relative intensity of the bands; relative ratios vs. GADPH.
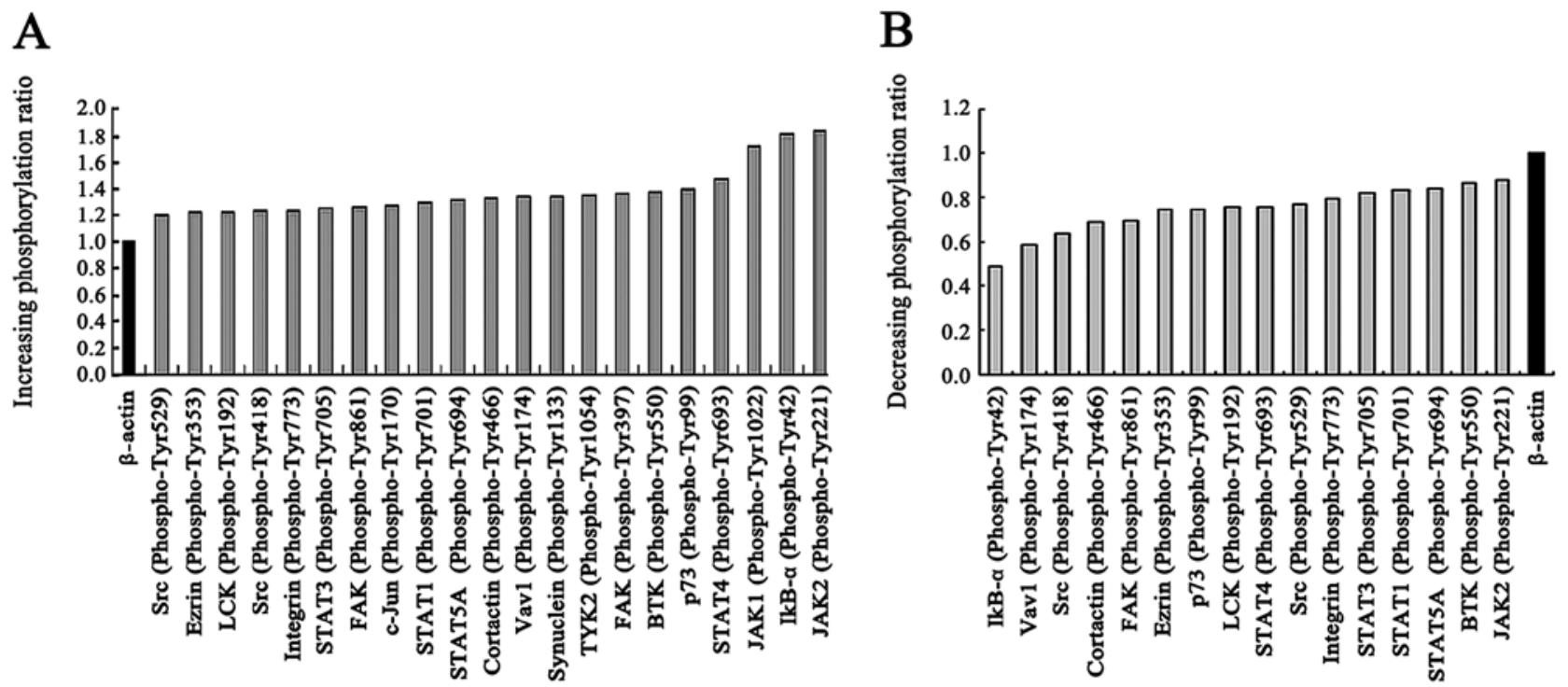

Figure 7. Tyrosine phosphorylation was investigated using an antibody microarray system in ricin toxin-binding subunit B (RTB)-treated RAW264.7 cells. The results from the 6 replicate samples were averaged, including the actin value. (A) Phosphorylation levels were increased at 20 sites in the RTB-treated RAW264.7 cells. (B) Decreasing effect of tyrosine kinase inhibitors on protein phosphorylation in RTB-treated RAW264.7 cells. The phosphorylation levels of 16 proteins (20 tyrosine sites) were specifically reduced.

the protein tyrosine kinase inhibitor, genistein, and assessed which kinases were inhibited in association with the suppressive effects in culture. A spectrum of proteins whose phosphorylation levels were increased or decreased by $>20$ or $15 \%$, with low $95 \%$ CI values were identified. Without the inhibitor, 20 of the 228 sites were positive for phosphorylation, and the highest value was observed for JAK2 Tyr221. Phosphorylation was found to be decreased at 52 sites (data not shown). Two tyrosines (Tyr418 and Tyr529) of the Src family were phosphorylated. The JAK1 Tyr1022, JAK2 Tyr221, STAT1 Tyr701, STAT3 Tyr705, STAT4 Tyr693, STAT5A Tyr694 and IкB- $\alpha$ Tyr42 phosphorylation levels were increased (Fig. 7A). Genistein reduced the phosphorylation of 16/288 tyrosine sites (Fig. 7B). Some of the identified proteins are associated with the downstream cascades of activated JAK-STAT and NF- $\kappa \mathrm{B}$ receptors.

\section{Discussion}

RTB is a galactose/N-acetyl-galactosamine-specific lectin (19). Although RTB alone is not toxic (20), it directly facilitates the translocation of RTA to the cytosol (21). In the present study, we demonstrate that recombinant RTB stimulates iNOS, TNF- $\alpha$ and IL-6 expression; this involves the activation of protein tyrosine kinase, NF- $\mathrm{B}$ and JAK-STAT signaling.

Macrophages respond to extracellular stimuli through phagocytosis. During the process of macrophage activation, 
many types of inflammatory mediators, such as IL-6, TNF- $\alpha$ and NO, are induced. The cellular responses to external intruders are commonly a complex array of phosphorylation cascades (22).

Previously, we found that the treatment of RAW264.7 cells with recombinant RTB results in a time- and dose-dependent production of NO (unpublished data), a finding that inspired us to study the in-depth mechanism of macrophage activation. The production of NO mediated by iNOS contributes to the killing of virally infected cells, tumor cells and certain pathogens $(23,24)$. The NO pathway, which is one of the major mechanisms involved, can be used to evaluate various immunomodulators of the innate immune system (25). It was observed that recombinant RTB directly induced the transcription of the iNOS gene and the expression of its protein, whereas this NO production by recombinant RTB was blocked by L-NMMA. We also found that recombinant RTB led to a time-dependent production of TNF- $\alpha$ and IL- 6 .

Previous studies have suggested the involvement of tyrosine kinases, $\mathrm{PI} 3 \mathrm{~K}$ and $\mathrm{PKC}$ in the NO production and macrophage activation induced by different agents $(26,27)$. In this study, we found that the co-treatment of macrophages with the tyrosine kinase inhibitor, genistein, the PI3K inhibitor, LY294002, and the PKC inhibitor, staurosporine, inhibited the production of RTB-induced NO to varying degrees. We also observed that the RTB-induced NO production was reduced in the cells co-treated with the JAK2 inhibitor, AG490. These results are in accordance with the reduction in RTB-induced iNOS gene transcription when the cells were co-treated with the pharmacological inhibitors, genistein, LY294002, staurosporine and AG490. These data suggest the possible role of tyrosine kinases, PI3K, PKC and JAK2 in the RTB-mediated macrophage activation. Among signaling molecules, MAPKs are recognized as important versatile signaling kinases that link upstream signaling events to macrophage activation $(22,28)$, and the activation of MAPKs involves changes in the expression of the AP-1 transcription factors, c-Fos and c-Jun (29). In our study, we also used the P42/44 inhibitor, PD98059, the p38 inhibitor, SB203580, and the JNK inhibitor, SP600125, and found that the RTB-induced NO production was sensitive to SB203580, although PD98059 and SP600125 had no effect. These results suggest the involvement of the p38 MAPK pathway in RTB-induced NO production. The activation of MAPKs controls the activation of NF- $\mathrm{kB}$ and plays a significant role in NO production $(30,31)$. The activation of NF- $\mathrm{kB}$ has been shown to be involved in the induction of iNOS production and the expression of various genes that are associated with immune and inflammatory responses $(32,33)$. LPS and various polysaccharides induce the activation of ERK and p38, whereas only p38 is involved in the induction of NF- $\mathrm{KB}$ DNA binding and the subsequent expression of iNOS and NO release in macrophages (30). In this study, we found that RTB-induced NO production was inhibited by the treatment of macrophages with the NF- $\mathrm{kB}$ inhibitor, BAY 11-7082, and iNOS gene expression was also inhibited by SB203580 and BAY 11-7082, suggesting that the p38 MAPK and NF- $\kappa B$ pathways are involved in the RTB-induced NO production. Recombinant RTB was found to induce a time-dependent production of TNF- $\alpha$ and IL-6, important mediators of immune modulation and inflammation. The maximum production of TNF- $\alpha$ was observed at $20 \mathrm{~h}$ of treatment with RTB, whereas that for IL-6 was observed at $24 \mathrm{~h}$. The inhibition of the protein production and gene expression of TNF- $\alpha$ and IL- 6 was observed in the macrophages treated with genistein, SB203580, LY294002, staurosporine, BAY 11-7082 and AG490, suggesting the possible involvement of tyrosine kinases, p38 MAPK, PI3K, PKC, NF-кB and JAK2. To investigate the role of NO in the modulation of TNF- $\alpha$ and IL-6 production in the RTB-treated macrophages, TNF- $\alpha$ and IL-6 expression levels were measured following treatment with the iNOS inhibitor, L-NMMA. The result that the production of TNF- $\alpha$ and IL- 6 was not significantly downregulated suggests that NO does not regulate TNF- $\alpha$ and IL- 6 production in macrophages following treatment with RTB.

Protein phosphorylation mediated by tyrosine kinases and the serine/threonine kinase involved in the production of NO, TNF- $\alpha$ and other cytokines in macrophages activated by agents such as LPS, interleukins and cisplatin has been reported $(34,35)$. To explore the tyrosine phosphorylation profiles of recombinant RTB-treated RAW264.7 cells with or without the protein tyrosine kinase inhibitor, genistein, we performed a phospho-proteomics-based study using a phospho-antibody microarray. This technique provides a high-throughput platform for efficient protein phosphorylation status profiling, with the detection and analysis of phosphorylation events at specific sites to identify whether the phosphorylation and activation levels in RAW264.7 cells were regulated by RTB. Based on the enhancement spectrum, our results indicated that signaling cascades, including the JAK-STAT and NF- $\mathrm{BB}$ pathways, were involved in the activation of phosphorylation induced by RTB in macrophages; furthermore, the activation of the phosphorylation of the JAK-STAT and NF- $\kappa$ B pathways induced by RTB was inhibited by genistein. These observations indicate the involvement of different signaling cascades in the activation of macrophages following treatment with recombinant RTB in vitro.

\section{References}

1. Falnes P and Sandvig K: Penetration of protein toxins into cells. Curr Opin Cell Biol 12: 407-413, 2000.

2. Stirpe $\mathrm{F}$ and Barbieri L: Ribosome-inactivating proteins up to date. FEBS Lett 195: 1-8, 1986

3. Audi J, Belson M, Patel M, Schier J and Osterloh J: Ricin poisoning a comprehensive review. JAMA 294: 2342-2351, 2005.

4. Tran H, Leong C, Loke WK, Dogovski C and Liu CQ: Surface plasmon resonance detection of ricin and horticultural ricin variants in environmental samples. Toxicon 52: 582-588, 2008.

5. Rapak A, Falnes PO and Olsnes S: Retrograde transport of mutant ricin to the endoplasmic reticulum with subsequent translocation to cytosol. Proc Natl Acad Sci USA 94: 3783-3788, 1997.

6. Sandvig K and van Deurs B: Delivery into cells: lessons learned from plant and bacterial toxins. Gene Ther 12: 865-872, 2005.

7. Choi NW, Estes MK and Langridge WH: Mucosal immunization with a ricin toxin B subunit-rotavirus NSP4 fusion protein stimulates a Th1. J Biotechnol 121: 272-283, 2006.

8. Medina-Bolivar F, Wright R, Funk V, Sentz D, Barroso L, Wilkins TD, Petri W Jr and Cramer CL: A non-toxic lectin for antigen delivery of plant-based mucosal vaccines. Vaccine 21: 997-1005, 2003.

9. Adams DO and Nathan CF: Molecular mechanisms in tumor-cell killing by activated macrophages. Immunol Today 4: 166-177, 1983.

10. Hamilton TA, Ohmori Y, Lebo JM and Kishore R: Regulation of macrophage gene expression by pro- and anti-inflammatory cytokines. Pathobiology 67: 241-244, 1999.

11. Schorey JS and Cooper AM: Macrophage signalling upon mycobacterial infection the MAP kinases lead the way. Cell Microbiol 5: 133-142, 2003. 
12. Gordon S: Pattern recognition receptors: doubling up for the innate immune response. Cell 111: 927-930, 2002.

13. Bolander FF Jr: The role of nitric oxide in the biological activity of prolactin in the mouse mammary gland. Mol Cell Endocrinol 174: 91-98, 2001.

14. Kozlowska K, Cichorek M, Wachulska M and Bautembach I: Role of interleukins and nitric oxide secretion by peritoneal macrophages in differential tumoricidal effect to transplantable melanomas as regarding their biological properties. Immunopharmacol Immunotoxicol 28: 305-317, 2006.

15. Michel T and Feron O: Nitric oxide synthases: which, where, how, and why? J Clin Invest 100: 2146-2152, 1997.

16. Mayer B and Hemmens B: Biosynthesis and action of nitric oxide in mammalian cells. Trends Biochem Sci 22: 477-481, 1997.

17. Korhonen R, Lahti A, Kankaanranta H and Moilanen E: Nitric oxide production and signaling in inflammation. Curr Drug Targets Inflamm Allergy 4: 471-479, 2005.

18. Kolb $\mathrm{H}$ and Kolb-Bachofen V: Nitric oxide in autoimmune disease: cytotoxic or regulatory mediator? Immunol Today 19 556-561, 1998

19. Gräslund S, Eklund M, Falk R, Uhlén M, Nygren PÅ and Ståhl S A novel affinity gene fusion system allowing protein A-based recovery of non-immunoglobulin gene products. J Biotechnol 99: 41-50, 2002.

20. Olsnes S and Pihl A: Different biological properties of the two constituent peptide chains of ricin, a toxic protein inhibiting protein synthesis. Biochemistry 12: 3121-3126, 1973.

21 Sharma S, Podder SK and Karande AA: Comparative studies on kinetics of inhibition of protein synthesis in intact cells by ricin and a conjugate of ricin B-chain with momordin. Mol Cell Biochem 200: 133-141, 1999.

22. Robinson MJ and Cobb MH: Mitogen-activated protein kinase pathways. Curr Opin Cell Biol 9: 180-186, 1997.

23. Lim S, Kang KW, Park SY, Kim SI, Choi YS, Kim ND, Lee KU, Lee HK and Pak YK: Inhibition of lipopolysaccharide-induced inducible nitric oxide synthase expression by a novel compound, mercaptopyrazine, through suppression of nuclear factor-kappaB binding to DNA. Biochem Pharmacol 68: 719-728, 2004.

24. Juang SH, Xie K, Xu L, Shi Q, Wang Y, Yoneda J and Fidler IJ: Suppression of tumorigenicity and metastasis of human renal carcinoma cells by infection with retroviral vectors harboring the murine inducible nitric oxide synthase gene. Hum Gene Ther 9 : 845-854, 1998
25. Pan D, Bera AK, Das S, Bandyopadhyay S, Rana T, Bandyopadhyay S, Das SK and Bhattacharya D: Use of zinc chloride as alternative stimulant for in vitro study of nitric oxideproduction pathway in avian splenocyte culture. Mol Biol Rep 37: 2223-2226, 2010.

26. Dong Z, Qi X, Xie K and Fidler IJ: Protein tyrosine kinase inhibitors decrease induction of nitric oxide synthase activity in lipopolysaccharide-responsive and lipopolysaccharide-nonresponsive murine macrophages. J Immunol 151: 2717-2724, 1993.

27. Shishodia S, Shrivastava A and Sodhi A: Protein kinase C: a potential pathway of macrophage activation with cisplatin. Immunol Lett 61: 179-186, 1998.

28. Lewis TS, Shapiro PS and Ahn NG: Signal transduction through MAP kinase cascades. Adv Cancer Res 74: 49-139, 1998.

29. Angel P and Karin M: The role of Jun, Fos and AP-1 complex in the cell-proliferation and transformation. Biochem Biophys Acta 1072: 129-157, 1991.

30. Chen CC and Wang JK: P38 but not p44/42 mitogen-activated protein kinase is required for nitric oxide synthase induction mediated by lipopolysaccharide in RAW264.7 macrophages. Mol Pharmacol 55: 481-488, 1999.

31. Yoon YD, Kang JS, Han SB, Park SK, Lee HS and Kim HM: Activation of mitogen-activated protein kinases and AP-1 by polysaccharide isolated from the radix of Platycodon grandiflorum in RAW264.7 cells. Int Immunopharmacol 4: 1477-1487, 2004.

32. Mendes AF, Carvalho AP, Caramona MM and Lopes MC: Role of nitric oxide in the activation of NF-kappaB, AP-1 and NOS II expression in articular chondrocytes. Inflamm Res 51: 369-375, 2002.

33. Connelly L, Palacios-Callender M, Ameixa C, Moncada S and Hobbs AJ: Biphasic regulation of NF-kappa B activity underlies the pro- and anti-inflammatory actions of nitric oxide. J Immunol 166: 3873-3881, 2001.

34. Eason SW and Martin W: Involvement of tyrosine kinase and protein kinase $\mathrm{C}$ in the induction of nitric oxide synthase by LPS and IFN- $\gamma$ in J774 macrophages. Arch Int Pharmacodyn Ther 330: 225-236, 1995.

35. Foulkes JG, Chow M, Gorka C, Frackelton AR Jr and Baltimore D: Purification and characterization of a protein tyrosine kinase encoded by the Abelson murine leukemia virus. J Biol Chem 260: 8070-8077, 1985. 